\title{
Hình ảnh không gian và văn hóa khoa học Phenikaa University
}

\author{
SDAG Lab \\ Centre for Interdisciplinary Social Research (ISR) \\ Trường ĐH Phenikaa \\ Yên Nghĩa, Hà Đông, Hà Nội, Việt Nam
}

ISR Phenikaa University, 15-10-2019. URL: http://isr.phenikaa-uni.edu.vn/chitiet/tintuc 2019222758 84/isr-no-luc-xay-dung-hinh-anh-khong-gian-va-van-hoa-nghiencuu-khoa-hoc-phenikaa-university.

Tháng 10 , tháng đầu tiên của quý 4, tiết trời chuyển sang se se với "sương lạnh chiều đông”. Sau 3 quý liên tục hối hả, vào lúc tưởng chừng như nhịp độ sẽ chậm lại để chuẩn bị cho một năm 2020 sôi nổi tiếp theo, Trung tâm ISR lại vẫn có dịp đóng góp cho 2 ngày lễ thương hiệu trường đại học Phenikaa.

Ngày thứ nhất là 10-10, kỷ niệm Giải phóng Thủ đô Hà Nội. Và ngày thứ hai là 14-11, ra mắt thương hiệu mới, sau gần một năm tròn kể từ khi mang tên trường Đại học Phenikaa, và bắt đầu quá trình đầu tư, đổi mới từ cơ sở vật chất, tới bộ máy quản lý và đội ngũ giảng viên - nghiên cứu viên.

Đóng góp của ISR là hai bài trên hệ thống xuất bản Nature Publishing Group. Tìm kiếm cụm từ "Phenikaa University" bằng Google trên Nature.com sẽ cho kết quả hai bài đầu tiên $[1,2]$ mang tên mới của trường trên www.nature.com, như trong Hình 1. 


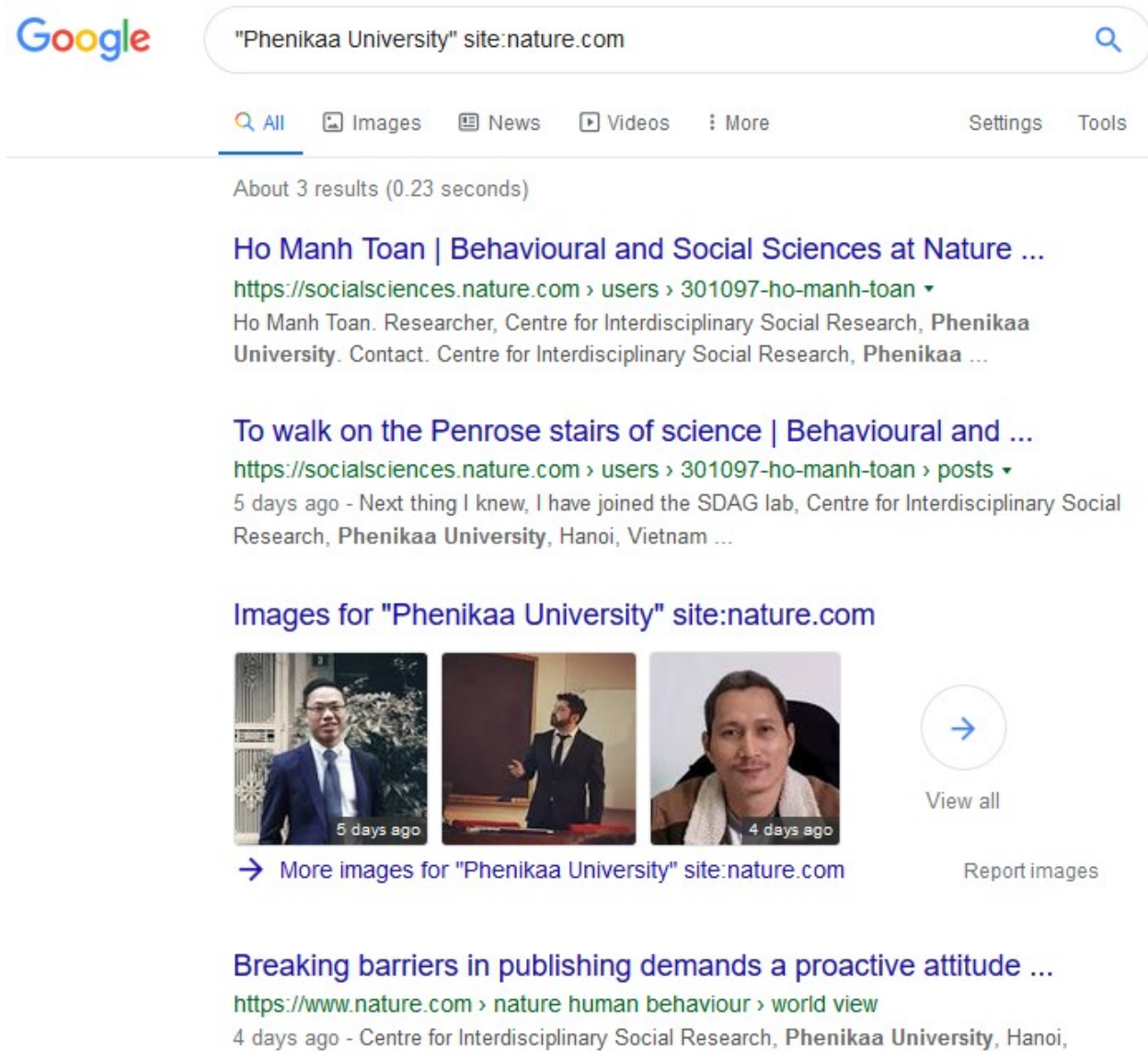

Hình 1: Tìm "Phenikaa University" trên nature.com bằng Google (truy cập: 15-10-2019)

Nói là đóng góp xây dựng hình ảnh trường ĐH Phenikaa, ở đây không chỉ mang ý nghĩa "bóng bẩy", mà còn là nghĩa đen. Khi mở bài [1] để đọc, không khó để nhận thấy ảnh của tác giả dẫn dắt bài, và toàn bộ nền ảnh chính là hình ảnh thực của trường.

Một không gian mới của Phenikaa University, với hình khối, cảnh quan, màu sắc và cây xanh, mang tính đại diện cao cho môi trường đào tạo và nghiên cứu mang lại một hình dung cụ thể và rõ nét cho độc giả quốc tế về một cái tên mới mẻ ở một quốc gia đang phát triển (xem Hình 2).

Trong bài [1], hành trình khoa học lâu dài, gian khó và đầy chất lý tưởng của đội ngũ còn rất trẻ, tất cả dưới 30 , hiện ra sâu lắng, đầy cảm xúc. Họ đang là một phần của thế hệ trẻ sớm mang trong tâm hồn tính cống hiến cho khoa học và đất nước. Đó là một loại "thương hiệu" khác: Văn hóa nghiên cứu khoa học. 


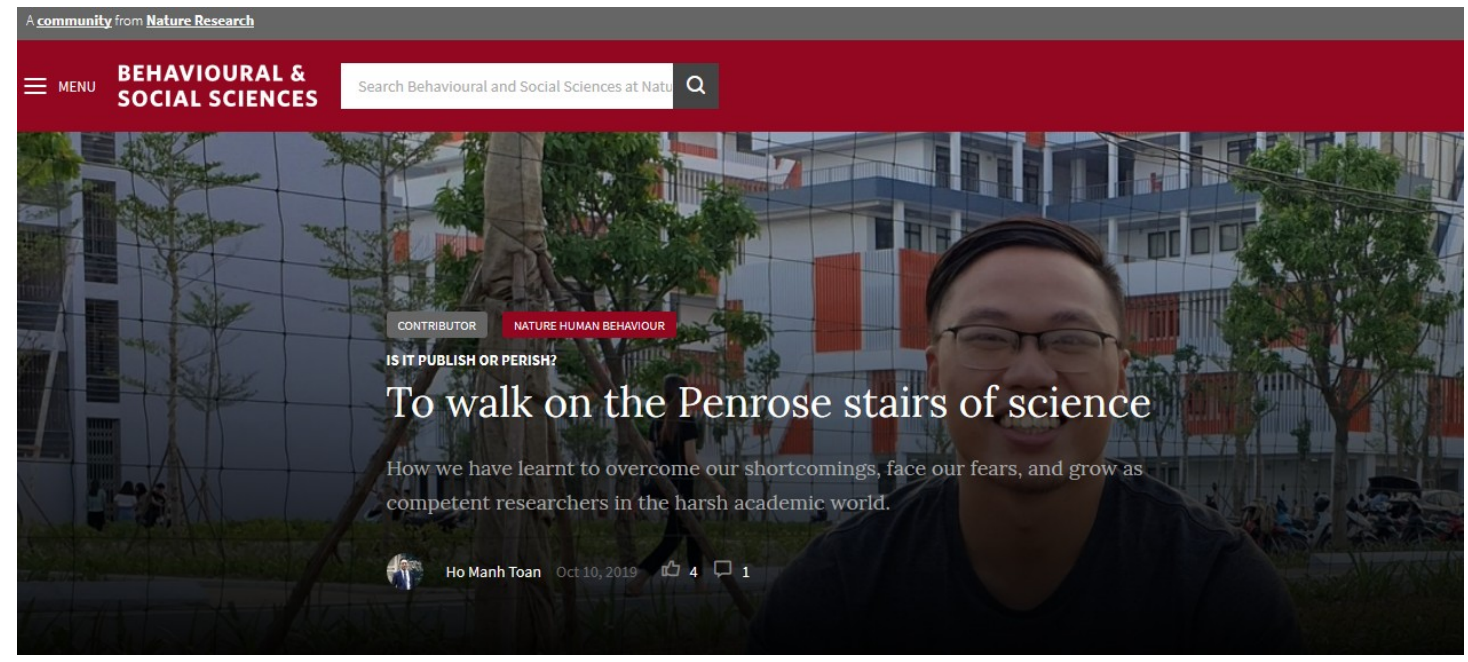

Hình 2: Hình ảnh đại diện Phenikaa Uni trên Nature Behavioural \& Social Sciences

Community (truy cập: 15-10-2019)

Chẳng bao lâu nữa, ngoài khái niệm "thăm trường" độc giả sẽ còn có dịp "thăm" một nơi chốn khác nữa. Đó là các tác phẩm, tư tưởng và đóng góp kiến thức của đội ngũ các tác giả ở trường.

Và những công việc này cứ diễn ra thầm lặng, từ mùa Thu này sang mùa Thu khác.

Vivat Veritas!

\section{Tham khảo:}

[1] Ho, M. T., et al. (2019). To walk on the Penrose stairs of science. Nature: Behavioural \& Social Sciences. Retrieved from: https://socialsciences.nature.com/users/ 301097-ho-manh-toan/posts/54541-to-walk-on-the-penrose-stairs-of-science (accessed: Oct 15, 2019).

[2] Vuong, Q. H. (2019). Breaking barriers in publishing demands a proactive attitude. Nature Human Behaviour 3(10): 1034. doi: 10.1038/s41562-019-0667-6. Retrieved from: https://www.nature.com/articles/s41562-019-0667-6. 